\title{
ACTH 1-24 inhibits proliferation of adrenocortical tumors in vivo
}

\author{
Oliver Zwermann, Dominik M Schulte ${ }^{1}$, Martin Reincke and Felix Beuschlein ${ }^{1}$ \\ Medizinische Klinik-Innenstadt, Ludwig Maximilians University, Munich, Germany and ${ }^{1}$ Division of Endocrinology and Metabolism, \\ Department of Internal Medicine II, Klinikum der Albert Ludwigs University, Freiburg, Germany
}

(Correspondence should be addressed to M Reincke; Email: martin.reincke@med.uni-muenchen.de)

\begin{abstract}
Objectives: Although several lines of evidence suggest that the overall effects of the ACTH receptor, melanocortin 2 receptor (MC2-R), mediated signal transduction on adrenocortical growth and tumorigenesis are anti-proliferative, activation of MC2-R induces mitogens like jun, fos, and myc and activates the MAPK pathway. In vivo, potential effects of endogenous ACTH on adrenal tumorigenesis can not be separated from effects of other POMC derived peptides.

Methods: Murine adrenocortical tumor cells that lack MC2-R expression ( $\left.6^{\mathrm{pcDNA}}\right)$ and $\mathrm{Y} 6$ cells stablely transfected with MC2-R ( $\left.6^{\mathrm{MC} 2-\mathrm{R}}\right)$ were generated. Presence of functional MC2-R was demonstrated by RT-PCR and Western blot using an antibody for phosphorylated CREB. As a syngenic tumor model, LaHeF1/J mice simultaneously received $10^{7} \mathrm{Y} 6^{\mathrm{MC} 2-\mathrm{R}}$ and $\mathrm{Y} 6^{\mathrm{pcDNA}}$ subcutaneously, giving rise to MC2-R positive and negative tumors within the same animal. Animals were treated for 3 weeks in groups of 12 according to the following schedule: group A, control animals receiving saline injection; group B, animals receiving $5.7 \mathrm{ng} /$ injection of a slow release formula of ACTH 1-24 administered i.p. three times a week (aiming at a low physiologic dose); and group C, animals receiving $57 \mathrm{ng} /$ injection of ACTH 1-24 (high physiological dose).

Results: Twenty days of ACTH 1-24 treatment did not significantly affect corticosterone levels, endogenous ACTH levels or adrenal and thymus weight compared with saline injection. However, ACTH 1-24 treatment of group B and C mice significantly reduced tumor weight in MC2-R positive tumors in a dose dependent manner $(P=0.03)$, while no significant difference in tumor mass was observed in MC2-R negative tumors. PCNA and TUNEL staining, together with morphological characterization, demonstrated that these in vivo effects were due to reduced proliferation, while apoptosis and cellular hypertrophy within the tumor remained unchanged.

Conclusion: MC2-R expression is associated with a less aggressive adrenal tumor phenotype and antiproliferative effects can be amplified through stimulation with physiological doses of ACTH.
\end{abstract}

European Journal of Endocrinology 153 435-444

\section{Introduction}

ACTH is the key mediator of pituitary dependent regulation of adrenal steroidogenesis. Binding of ACTH to its cognate receptor (melanocortin 2 receptor; MC2-R) is followed by activation of several pathways, including protein kinase A (PKA) (1), PKC, MAP kinases (2), and phospholipase $\mathrm{C}$, as well as calcium channel activation (3). In accordance with these diverse effects induced by ACTH on a molecular level, MC2-R dependent pathways have been implicated not only in the regulation of steroidogenesis but also in the regulation of adrenocortical growth, differentiation and tumorigenesis.

Adrenocortical carcinoma (ACC) is a rare but highly malignant endocrine tumor entity with overall poor long-term therapeutic options. Although recent years have witnessed considerable progress in the understanding of the molecular basis of ACC development (4), detailed characterization of potential mediators of adrenal tumor growth is warranted. Adrenocortical tumorigenesis differs from pituitary and thyroid tumorigenesis because constitutional activation of the cAMP/PKA pathway by activating point mutations of a G-protein coupled receptor, i.e. the MC2-R, or in the $\alpha$-chain of the stimulatory G-protein (Gs $\alpha$, GNAS) has not been identified in benign and malign adrenocortical tumors (5-7). However, the McCune-Albright Syndrome, that is caused by mutations in the Gs $\alpha$ gene, is associated with bilateral adrenal hyperplasia and GNAS1 gene mutations could also be identified in sporadic macronodular adrenal hyperplasia (8). On the contrary, activating mutations of the Gi2, one of the 
adenylate cyclase inhibitory G-proteins, has been found in some adrenocortical tumors, while these findings could not be confirmed in another series of adrenocortical tumors $(7,9)$. In addition, an association between loss of heterozygosity ( $\mathrm{LOH}$ ) of the MC2-R gene, resulting in reduced expression of MC2-R mRNA with an advanced tumor stage, and a more rapid clinical course than in carcinoma patients without $\mathrm{LOH}$ has been demonstrated (10-12). While these data suggest that allelic loss of the MC2-R gene in adrenocortical tumors is associated with loss of differentiation, a characteristic feature of human tumorigenesis, it is not clear whether the lack of MC2-R expression is a causative event resulting in a growth advantage and clonal expansion of a malignant cell clone.

In vivo, inactivating mutations of the MC2-R are the cause of isolated familial glucocorticoid deficiency, which is characterized by ACTH insensitivity and adrenal hypoplasia (13). Accordingly, hypophysectomy and suppression of endogenous ACTH by glucocorticoid treatment results in decreased adrenal volume (14). Conversely, ACTH supplementation can prevent adrenal atrophy following hypophysectomy (14) and administration of high doses of ACTH leads to hypertrophy of the adrenal cortex $(15,16)$, a fact that is clinically relevant in patients with congenital adrenal hyperplasia. Moreover, ACTH treatment has been demonstrated to result in increased adrenocortical cell proliferation in guinea pigs (17, 18 ) and rats (19). However, there is compelling evidence indicating that ACTH is not the only proopiomelanocortin (POMC)-derived peptide with effects on adrenocortical growth and a mitogenic peptide resides in the pro- $\gamma$-melanocyte stimulating hormone (MSH) fraction of the POMC peptide $(20,21)$. Although the pro- $\gamma$-MSH peptide itself does not have mitogenic potential, it has been suggested that the specific cleavage of 1-76 POMC after its secretion from the pituitary is required to release shorter fragments that exhibit potent mitogenic actions on adrenal cells $(20-23)$

In vitro experiments evaluating effects of ACTH on adrenocortical tumor growth have been performed since the early 1970s utilizing the murine adrenocortical tumor cell line Y1. These experiments have demonstrated the growth inhibiting effect of ACTH (24-26) and similar results have been obtained in rat, bovine and human primary cell cultures (27-30). However, these findings have been challenged by other in vitro experiments demonstrating ACTH induced increase in DNA synthesis and cell growth in human (31-33) and rat (32-34) primary adrenal cells, while biphasic effects on cellular hypertrophy and proliferation have been found under special experimental conditions $(2,34)$. As further indirect evidence of growth promoting effects upon ACTH treatment, ACTH has been shown to induce potential oncogenes like jun and fos $(35,36)$. Because cell culture conditions, ACTH prep- arations, dosage of ACTH and observational periods varied between the different studies and these experiments are poorly comparable and show limited predictive value for in vivo outcome on adrenal tumorigenesis.

Herein, we present an in vivo model for the investigation of effects of MC2-R dependent pathways on adrenal tumor growth using the Y6 cell line, which have been demonstrated to lack MC2-R expression (37). While resistant to ACTH, Y6 cells retain signaling induced by forskolin and signal transduction pathways have been reported to be intact as transfection of an MC2-R expression led to expression of functional receptors (38). Using this well defined and controlled tumor model, we provide evidence that physiological doses of ACTH inhibit adrenal tumor growth defining ACTH and its receptor as a possible tumor suppressor genes for adrenocortical carcinoma.

\section{Materials and methods}

\section{Generation of MC2-R expressing Y6 cells}

Cloning of the full length coding sequence of the human MC2-R gene (kind gift of R Cone) into the mammalian expression vector pcDNA 3.1 (Invitrogen, Karlsruhe, Germany) was performed via XhoI and NotI restriction sites and T4 ligase (Promega, Mannheim, Germany) and orientation and sequence was verified by direct sequencing. Murine adrenocortical Y6 cells (kind gift of B Schimmer) were transfected with the expression plasmid encoding hMC2-R (pcDNA-MC2-R) or with the empty vector (pcDNA 3.1) using ExGen reagent (Fermentas, St Leon Roth, Germany) following the instructions of the manufacturer. After 2 days in standard medium, cells were kept under selection medium containing $50 \mathrm{mg} / \mathrm{ml}$ neomycin (Geneticin, Invitrogen). Resistant cell clones were picked, expanded and diluted three times to ensure monoclonality. After dilution five clones were further maintained and one clone, with the highest MC2R expression indicated by rounding of the cells upon ACTH treatment, was selected for further experiments.

\section{Isolation of RNA and reverse transcription- polymerase chain reaction (RT-PCR)}

Total RNA was extracted from cells and tumor tissues, respectively, using the SV40 total RNA kit (Promega, Mannheim, Germany). One $\mu \mathrm{g}$ of RNA was reverse transcribed with Supersript II MMLV reverse transcriptase and dT18 primers (Invitrogen). One hundred ng cDNA were subjected to PCR amplification with PCR conditions as follows: $5 \mathrm{~min}$ at $95^{\circ} \mathrm{C}$, followed by 35 cycles with $1 \mathrm{~min}$ at $95^{\circ} \mathrm{C}, 1 \mathrm{~min}$ at $60^{\circ} \mathrm{C}$, and $1 \mathrm{~min}$ at $72{ }^{\circ} \mathrm{C}$ and final extension for $5 \mathrm{~min}$ at $72{ }^{\circ} \mathrm{C}$. Primers were $5^{\prime}$ CATGGGCTATCTCAAGCCAC $3^{\prime}$ and $5^{\prime}$ GAGATCTTCCTGGTGTGGGATC3' for human MC2-R and 
5'GCCTGTCAAGCA TTAGTGACAA $3^{\prime}$ and 5'CTGCCACGAGGCTTAAGATAAC3' for mouse MC2-R. B2microglobulin served as a control for intact RNA and was amplified using the primers $5^{\prime}$ GCTATCCAGAAAACCCCTCAA $3^{\prime}$ and 5'CATGTCTCGATCCCAGTAGACGGT3'. DNA contamination was excluded by control experiments without reverse transcription.

Expression of melanocortin receptor 1 was investigated by RT-PCR with primers as published previously (39). PCR conditions were the same as described above, but annealing temperature was $57^{\circ} \mathrm{C}$. PCR products were loaded onto a $1 \%$ agarose gel and analyzed after ethidium bromide staining.

\section{Western blot}

For determination of MC2-R function in transfected cells, $\mathrm{Y} 6^{\mathrm{MC} 2-\mathrm{R}}$ and $\mathrm{Y} 6^{\mathrm{pcDNA}}$ were grown in six well plates. Cells were incubated in $1 \mathrm{mM}$ isobutylmethylxantine (IBMX) for $1 \mathrm{~h}$ and thereafter $10^{-6} \mathrm{M} \mathrm{ACTH}$ $1-24,10^{-5} \mathrm{M}$ forskolin or phosphate buffered saline was added. After $15 \mathrm{~min}$, cells were harvested in RIPA buffer and the lysate was rocked for $2 \mathrm{~h}$ and heated to $95^{\circ} \mathrm{C}$ for $10 \mathrm{~min}$. $20 \mu \mathrm{g}$ protein were loaded on a $12 \%$ SDS polyacrylamide gel and blotted to a nitrocellulose membrane. Blots were blocked in 5\% non fat milk powder, and incubated overnight with an antibody for phosphorylated CREB (Sigma, Munich, Germany) or total CREB (Cell Signaling Technology, Beverly, MA, USA). Horseradish peroxidase linked anti rabbit antibody (Amersham, Freiburg, Germany) was used as a secondary antibody followed by detection with the ECL plus kit (Amersham).

\section{Animal experiments}

All experiments involving animals were performed in accordance with institutionally approved and current animal care guidelines. LaHeF1/J mice were generated as F1 hybrids from male AHe/J and female C57L/J mice (Jackson Laboratory, Bar Harbor, MN, USA), and mice with an average age of 4.5 months and with an weight of 26-34g were used for the study. All animals were maintained under standard conditions of temperature $\left(22^{\circ} \mathrm{C}\right)$ and lighting (12L: 12D) and food and water was given ad libidum. $10^{7}$ cells $\mathrm{Y} 6^{\mathrm{MC} 2-\mathrm{R}}$ and $\mathrm{Y} 6^{\mathrm{pcDNA}}$, respectively, were injected subcutaneously to the right and left side of the neck on day 0. ACTH 1-24 in a slow release formula (Synacthen depot, Novartis, Erlangen, Germany) was injected at two dosages (5.7 and $57 \mathrm{ng}$ /injection) i.p. on days 1, 2 and 3 and then three times a week, corresponding to a low and high physiological dosage, respectively. Control mice received i.p. saline injections accordingly. 12 mice per group were studied. On day 20, mice were euthanized between $0800 \mathrm{~h}$ and $1100 \mathrm{~h}$ using isofluran and blood was drawn by cardiac puncture within $60 \mathrm{~s}$ of initial handling. Tumors were dissected from adjacent tissue,
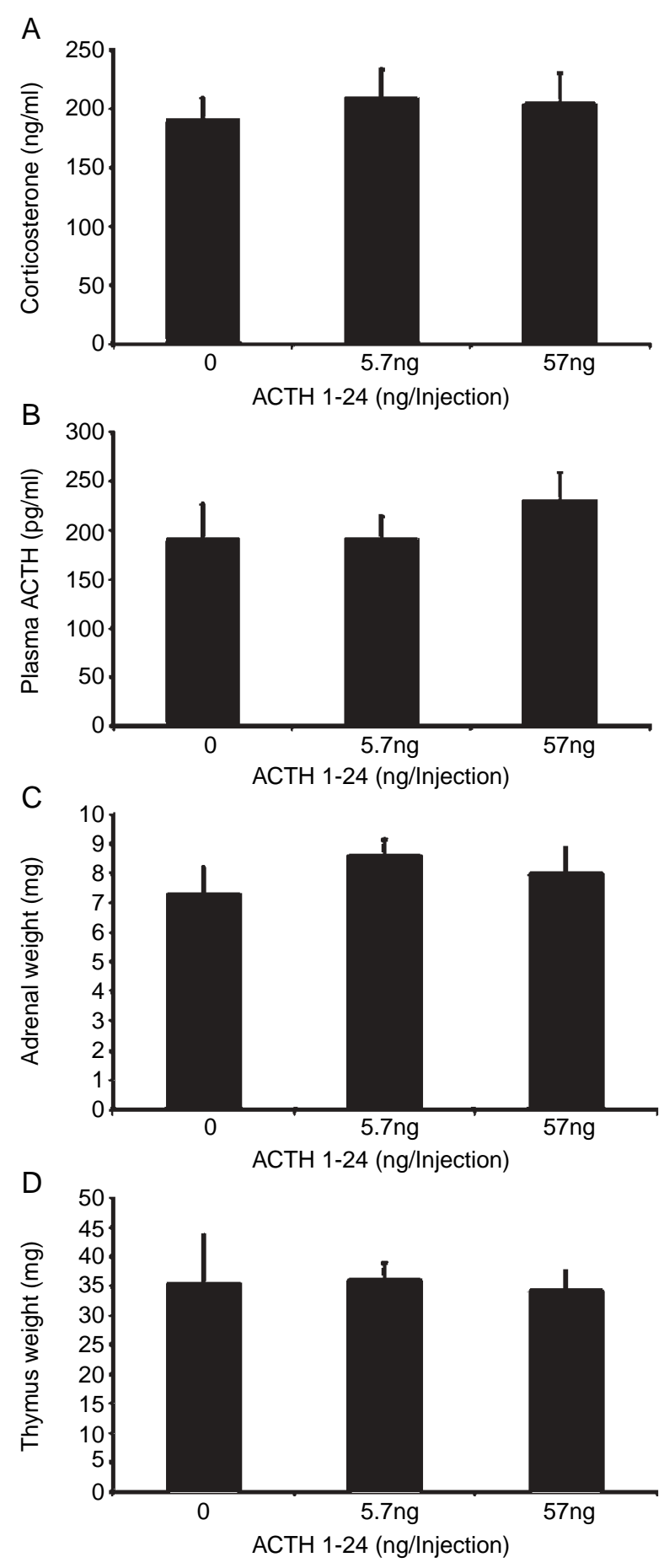

Figure 1 (A) Effects of exogenous ACTH 1-24 treatment on corticosterone levels, (B) endogenous plasma ACTH levels, (C) adrenal weight and (D) thymus weight, suggesting lack of significant changes on the assessed markers. On day 20, 48h after the last injection, the tumor bearing mice were euthanized and blood was drawn for measurement of corticosterone and ACTH. Adrenals and thymus glands were dissected and weight was determined. 
weighed and snap-frozen in liquid nitrogen or fixed in $4 \%$ paraformaldehyde. As in vivo controls of ACTH bioactivity, adrenal and thymus weight were determined after preparation of the organs.

\section{Hormone measurements}

Plasma ACTH concentration, as depicted in Fig. 1, was measured using a commercial two site assay (Nichols Advantage, ACTH Assay, Nichols Institute Diagnostics, San Clemente, CA, USA) which has a cross reactivity of approximately $1 \%$ with synthetic ACTH 1-24. In addition, for dose finding studies, total ACTH plasma levels were measured with an assay that detects murine endogenous and synthetic ACTH 1-24 with a specifity of $100 \%$ (DSL-2300, Webster, TX, USA). Plasma corticosterone was determined by radioimmunoassay (RIA) using an ${ }^{125}$ I RIA kit according to the manufacturer's protocols (ICN Biomedical, Costa Mesa, CA, USA).

\section{Cell counts}

Hematoxylin-eosin stained tumor sections were examined with a standard light microscope using $400 \times$ magnification. Cell nuclei of three independent tumor sections from three different animals per group were counted under standardized conditions. Cell counts were expressed as cell number/high power field (HPF).

\section{Immunohistochemistry}

For PCNA immunohistochemistry, paraffin embedded tumor sections were rehydrated and incubated overnight with a rabbit polyclonal antibody (Santa-Cruz Biotechnology, Santa Cruz, CA, USA) in a dilution of 1:100 in blocking buffer containing 3\% bovine serum albumin (BioRad, Munich, Germany), 5\% goat serum (DAKO, Hamburg, Germany), and 0.5\% Tween 20. Bound antibody was detected by horseradish peroxidase linked anti-rabbit-IgG (Amersham) and staining with DAB (Sigma) after blockage of endogenous peroxidase with 0.6 hydrogen peroxide in methanol. Sections treated accordingly, but without incubation with primary antibody served as a negative control. Sections were lightly counter-stained with hematoxylin and percentage of positive cells was determined counting 5 HPFs per section.

Detection of apoptotic cells in paraffin embedded tumor sections was performed using the dead-end TUNEL assay (Promega) following the instructions of the manufacturer.

\section{Statistical analysis}

All results are expressed as mean \pm S.E.M. Statistical comparisons were analyzed by ANOVA and Fisher's protective least significant difference test using Stat View (SAS Institute, Cary, NC, USA). Statistical significance was defined as $P<0.05$ and is indicated as a asterisk $(*)$ or cross $(\dagger)$ in the figures.
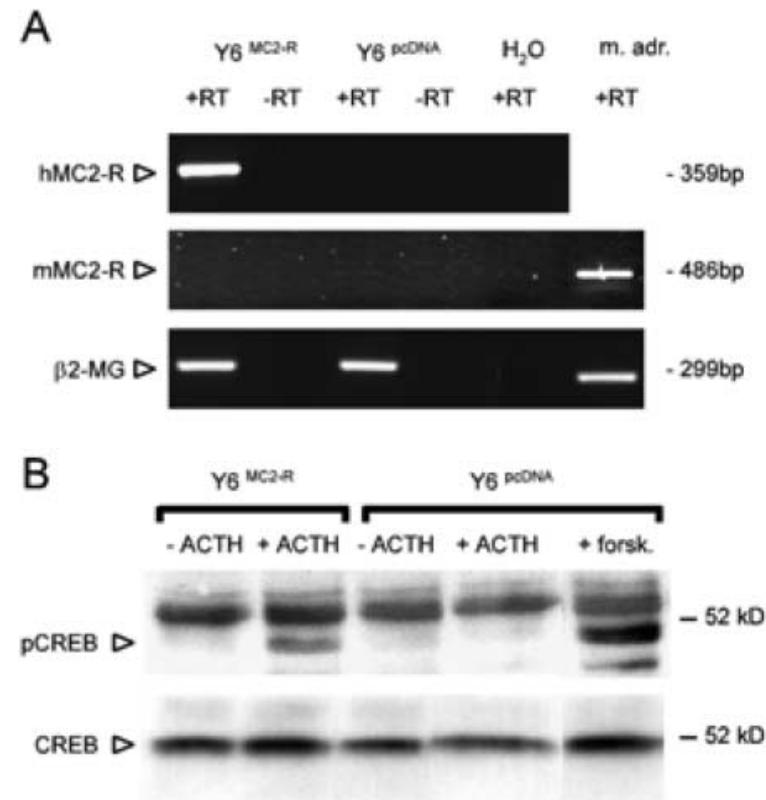

Figure 2 (A) RT-PCR demonstrating expression of human ACTH receptor (hMC2-R) mRNA in Y6 cells following stable transfection $\left(\mathrm{Y}^{\mathrm{MC2}-\mathrm{R}}\right)$ while endogenous murine $\mathrm{MC2}-\mathrm{R}$ (mMC2-R) is not expressed. A mouse adrenal cDNA (m. adr.) served as a positive control. DNA contamination was excluded by samples without reverse transcription (-RT). Y $6^{\text {pcDNA }}$ denotes control cells transfected with empty vector. (B) Western blotting demonstrating induction of phosphorylated CREB (P-CREB) only in Y6 ${ }^{\mathrm{MC} 2-\mathrm{R}}$ cells after ACTH treatment, indicating restoration of $\mathrm{MC2}-\mathrm{R}$ function. In MC2- $\mathrm{R}$ negative cells $\left(Y 6^{\mathrm{pcDNA}}\right)$ forskolin served as a positive control.

\section{Results}

\section{Transfection of hMC2-R expression vector reconstitutes functional MC2-R in Y6 cells}

Transfection of Y6 cells with a human MC2-R encoding cDNA resulted in stable expression of hMC2-R mRNA in $\mathrm{Y}^{\mathrm{MC} 2-\mathrm{R}}$, while expression of endogenous $\mathrm{mMC2}-\mathrm{R}$ was excluded in both $\mathrm{Y} 6^{\mathrm{MC} 2-\mathrm{R}}$ and $\mathrm{Y} 6^{\mathrm{pcDNA}}$ by RTPCR (Fig. 2A). Functionality of the transfected receptor was demonstrated by stimulation of the cells with ACTH 1-24 and subsequent detection of phosphorylated CREB (pCREB) by western blotting. As expected, increase in pCREB protein levels was induced upon stimulation with ACTH in $\mathrm{Y}^{\mathrm{MC} 2-\mathrm{R}}$, while pCREB remained undetectable in ACTH treated $\mathrm{Y}^{\mathrm{pcDNA}}$ cells (Fig. 2B). As a positive control, increase in intracellular cAMP levels by forskolin treatment demonstrated increase in CREB phosphorylation.

\section{Applied ACTH treatment regimes do not result in overt hypercortisolism}

During the observation period of 20 days, ACTH 1-24 was injected intra-peritoneally with two different 
dosages, while control animals received saline injections at the same intervals. While 12 animals were assigned to every group, one mouse receiving $5.7 \mathrm{ng}$ ACTH 1-24 showed signs of suffering and was euthanized before completion of the study. Preliminary dose finding studies were performed to titrate synacthen doses that would result in low or high physiological ACTH levels. Plasma ACTH levels, which were determined with an assay that detects both endogenous and 1-24 ACTH, increased over baseline $(180 \mathrm{pg} / \mathrm{ml})$ over the $48 \mathrm{~h}$ observation period after injection of $57 \mathrm{ng}$ ACTH1-24 (high physiological dose) with a peak value around $24 \mathrm{~h}$ after injection $(376 \pm 17 \mathrm{pg} / \mathrm{ml})$ and substantial decrease thereafter $(79 \pm 5 \mathrm{pg} / \mathrm{ml})$.

In accordance with these results, ACTH treatment regimens aiming at low and high physiological doses did not significantly affect corticosterone and ACTH levels measured $48 \mathrm{~h}$ after the last injection $(5.7 \mathrm{ng}$, $208.8 \pm \quad 24.3 \mathrm{ng} / \mathrm{ml} \quad(P=0.61) ; \quad 57 \mathrm{ng}, \quad 204.2 \pm$ $26.2 \mathrm{ng} / \mathrm{ml}(P=0.69)$ vs $191.0 \pm 18.2 \mathrm{ng} / \mathrm{ml}$ in saline treated animals and $5.7 \mathrm{ng}, \quad 191.0 \pm 22.5 \mathrm{ng} / \mathrm{ml}$ $(P=0.98) ; 57 \mathrm{ng}, 230.6 \pm 28.1 \mathrm{ng} / \mathrm{ml}(P=0.35)$ vs $191.9 \pm 34.5 \mathrm{ng} / \mathrm{ml}$ in saline treated animals, respectively; Figs $1 \mathrm{~A}$ and $\mathrm{B})$. To further evaluate the possible long term biological effects of ACTH 1-24 treatment regimens, adrenal weight (as a measure of ACTH induced adrenal hypertrophy) and thymus weight (as a measure of glucocorticoid excess) were monitored. In accordance with the comparable hormone levels between the groups, ACTH 1-24 treatment had no significant effect on adrenal weights $(5.7 \mathrm{ng}, 8.6 \pm 0.5 \mathrm{mg}(P=0.45) ; 57 \mathrm{ng}$, $8.0 \pm 0.8 \mathrm{mg}(P=0.67)$ vs $7.3 \pm 0.9 \mathrm{mg}$ in saline treated animals; Fig. 1C) or thymus weights $(5.7 \mathrm{ng}, 36 \pm 3 \mathrm{mg}$ $(P=0.9) ; 57 \mathrm{ng}, 34 \pm 3 \mathrm{mg}(P=0.8)$ vs $35 \pm 8 \mathrm{mg}$ in saline treated animals; Fig. 1D). Taken together, these results indicate that the amount of injected ACTH 124 , which was calculated to aim at low and high physiological levels, did not induce significant perturbation of the HPA axis or overt hypercortisolism.

\section{ACTH treatment results in lower weight of MC2-R expressing tumors}

Subcutaneous injection of MC2-R positive and negative cells into the neck of $\mathrm{LaHeF} 1 / \mathrm{J}$ mice resulted in palpable tumors within 20 days (Fig. 3A). Overall, MC2-R expression in $\mathrm{Y} 6$ derived tumors was associated with a lower tumor weight (saline, $1242 \pm 160 \mathrm{mg}\left(\mathrm{Y}^{\mathrm{MC} 2-}\right.$ $\left.{ }^{\mathrm{R}}\right)$ vs $1692 \pm 219 \mathrm{mg}\left(\mathrm{Y}^{\mathrm{pcDNA}}\right) \quad(P=0.09) ; 5.7 \mathrm{ng}$ ACTH $1-24, \quad 748 \pm 147 \mathrm{mg}$ vs $1416 \pm 147 \mathrm{mg}$, $(P=0.02) ; \quad 57 \mathrm{ng} \quad$ ACTH $1-24, \quad 657 \pm 140 \mathrm{mg} \quad$ vs $1398 \pm 275 \mathrm{mg}(P=0.007)$; Fig. 3B $)$. In addition, ACTH 1-24 treatment further reduced tumor weight in MC2-R positive tumors (5.7 ng ACTH 1-24, $748 \pm 147 \mathrm{mg} \quad(P=0.07) ; \quad 57 \mathrm{ng}$ АCTH $1-24$, $657 \pm 140 \mathrm{mg}(P=0.03)$ vs saline, $1242 \pm 160 \mathrm{mg})$ while weight of MC2-R negative tumors was not significantly affected by ACTH treatment (5.7 ng ACTH 1-24,
$1416 \pm 147 \mathrm{mg} \quad(P=0.31) ; \quad 57 \mathrm{ng}$ ACTH $1-24$, $1398 \pm 275 \mathrm{mg}, P=0.27$ vs saline, $1692 \pm 219 \mathrm{mg}$; Fig. 3B). Taken together, these results demonstrate an association with a less aggressive phenotype in adrenal tumors expressing MC2-R in comparison to MC2-R negative tumors which can be further amplified by exogenous ACTH treatment.

\section{ACTH treatment inhibits proliferation in MC2-R expressing tumors}

Since ACTH 1-24 induced reduction in tumor weight could be due to suppression of proliferation, induction of apoptosis or reduction of cell volume, PCNA immunohistochemistry, TUNEL staining and cell counts per HPF were analyzed in the different tumor samples. While the number of PCNA positive cells was not affected in MC2R negative tumors (5.7 ng ACTH $1-24, \quad 56.5 \pm 2.5 \%$ $(P=0.16) ; 57 \mathrm{ng}$ ACTH $1-24,59.3 \pm 2.3 \%(P=0.61)$ vs saline, $58.0 \pm 2.1 \%$; Fig. 4 A-E), PCNA expression was significantly reduced with increasing doses of ACTH in MC2-R expressing tumors (5.7 ng ACTH 1-24, $51.2 \pm 3.3 \%(P=0.56) ; 57 \mathrm{ng}$ ACTH $1-24,39.6 \pm 1.4 \%$
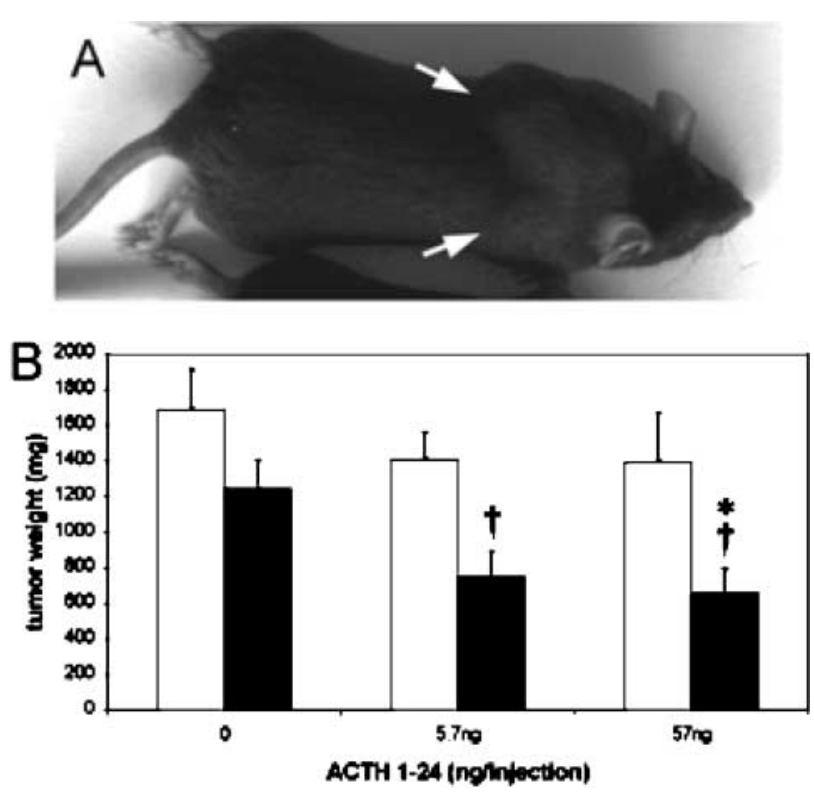

Figure 3 (A) Example of a mouse 20 days after injection of $\mathrm{Y}^{\mathrm{MC2}-}$ ${ }^{R}$ cells (right neck region) and $Y 6^{\text {pcDNA }}$ cells (left neck region) after treatment with a low physiological dose ACTH 1-24 over a period of 20 days demonstrating smaller tumor size in the MC2-R positive tumor. (B) Weights from MC2-R negative tumors ( $Y 6^{\text {pcDNA }}$, white bars) and MC2-R positive tumors ( $\mathrm{Y}^{\mathrm{Mc}}{ }^{\mathrm{C}-\mathrm{R}}$, black bars) demonstrating lower tumor burden in MC2-R expressing tumors with significant decrease in tumor weight upon ACTH treatment. $\left(^{*}\right)$ denotes significant changes compared with untreated mice, $(\dagger)$ denotes significant changes between tumors within one treatment group. 
$(P<0.02)$ vs saline, $60.8 \pm 2.1 \%$; Fig. $4 \mathrm{~A}-\mathrm{E})$. In contrast, apoptosis was not affected by MC2-R expression or ACTH treatment in a significant manner ( $6^{\text {pcDNA }}: 5.7 \mathrm{ng}$ ACTH $1-24, \quad 5.4 \pm 2.0 \% \quad(P=0.95) ; 57 \mathrm{ng}$ ACTH 1-24, $5.0 \pm 0.9 \%,(P=0.84)$ vs saline, $5.6 \pm 1.8 \%$; Y6 ${ }^{\mathrm{MC} 2-\mathrm{R}}$ : $5.7 \mathrm{ng}$ ACTH $1-24,5.0 \pm 0.7 \%(P=0.83) ; 57 \mathrm{ng}$ АCTH $1-24,6.8 \pm 1.1 \%(P=0.46)$ vs saline, 5.4 $1.8 \%$; Fig. $4 \mathrm{~F}-\mathrm{J})$. Similarly, cell number per HPF as a marker of cellular hypertrophy was not affected by MC2-R expression or

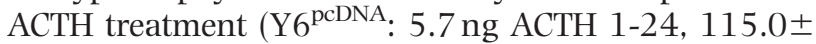
$3.2 \% \quad(P=0.12) ; 57 n g$ ACTH $1-24,127.8 \pm 3.1 \%$ $(\mathrm{P}=0.8) \quad$ vs $\quad$ saline, $125.4 \pm 5.3 \% ; \quad \mathrm{Y} 6^{\mathrm{MC} 2-\mathrm{R}}: 5.7 \mathrm{ng}$ ACTH 1-24, 121.4 $1.3 \%(P=0,17) ; 57 \mathrm{ng}$ ACTH $1-$ $24,125.0 \pm 9.0 \%(P=0.09)$ vs saline, $108.2 \pm 5.6 \%$; Fig. $4 \mathrm{~K}-\mathrm{O})$. Taken together, these results indicate that the observed effects of ACTH on tumor growth are mainly mediated by suppression of cellular proliferation.

\section{Transfected Y6 derived tumors retain MC2-R expression but lose MC1-R expression}

As regain of endogenous MC2-R expression in Y6 cells after passage in mice has been reported (37) and to assess possible changes in the expression pattern in the tumor samples that would affect ACTH responsiveness, expression of MC2-R and MSH receptor (melanocortin 1 receptor (MC1-R)) was evaluated in a subset of tumors. Analysis of the tumors for human and mouse MC2-R expression excluded loss of human MC2R expression after passage in the animals, whereas murine MC2-R mRNA expression remained undetectable (Fig. 5A) in all tumor samples studied. In addition, although the parent Y6 cell lines used in our experiments showed expression of MC1-R, this expression was lost in both the MC2-R positive and MC2-R negative tumor
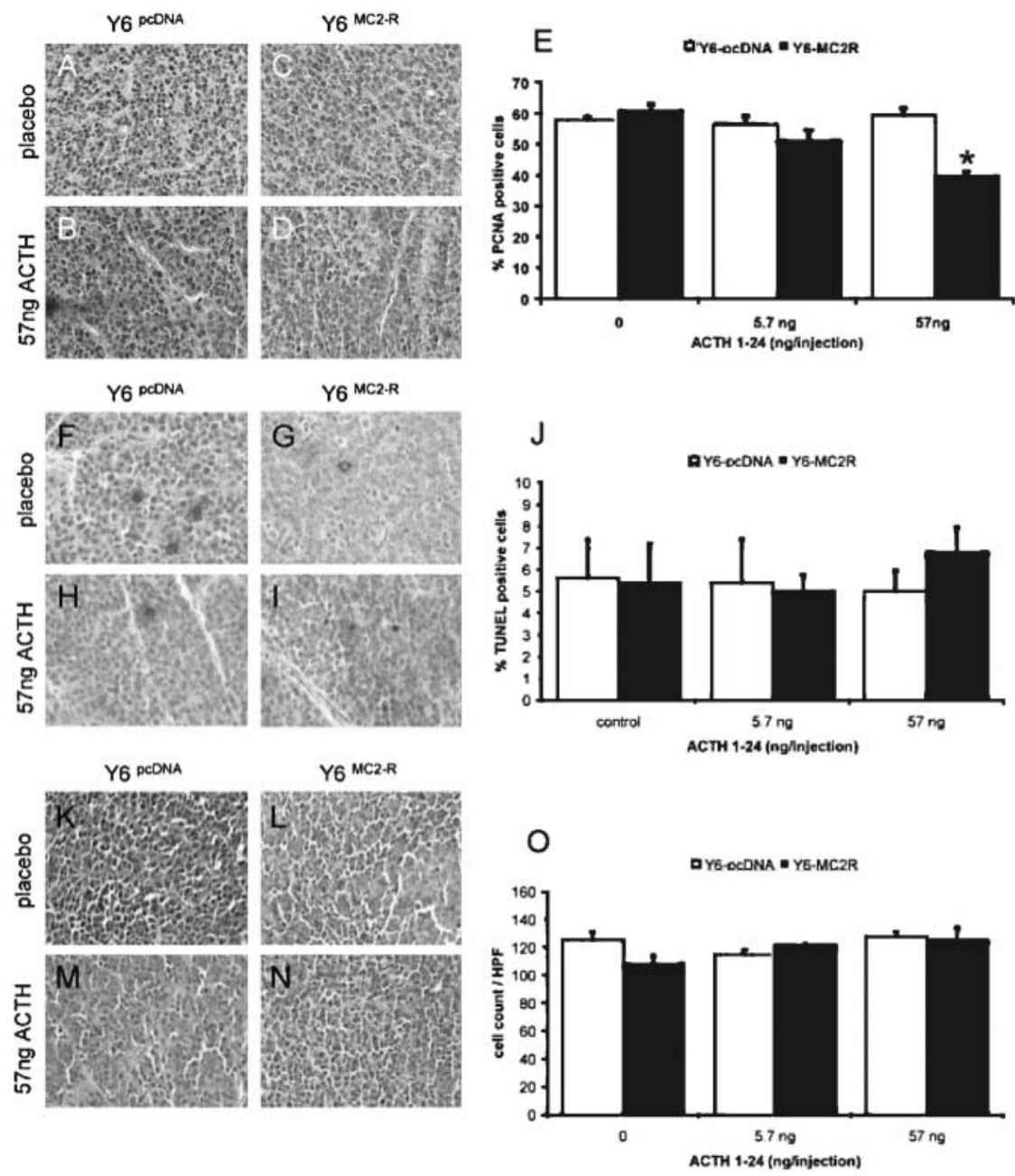

Figure 4 A-E: PCNA staining in untreated $(A, C)$ and ACTH treated $(B, D)$ tumors expressing $(C, D)$ or lacking $(A, B) M C 2-R$ expression and quantification demonstrating significant decrease in PCNA positive nuclei only in ACTH treated MC2-R expressing tumors (E). (F-J) No significant changes in TUNEL staining independent of ACTH treatment and MC2-R expression was detectable. $(\mathrm{K}-\mathrm{O})$ No differences in cell number per high power field (HPF) was assessed in treated and untreated tumors independently of MC2-R expression. 
samples after in vivo growth. Taken together, these results indicate, that although retaining their expression pattern with regards to the transfected MC2-R, the tumors display changes in expression pattern of endogenous MC1-R possibly reflecting genetic instability of the tumor clone.

\section{Discussion}

While the mechanisms of steroid hormone production have been characterized in quite some detail, little is known about the regulatory factors that are responsible for the proliferation and differentiation of steroidogenic cells. As for the adrenal cortex, there is an increasing body of evidence suggesting that ACTH, in addition to its role in the regulation of steroidogenesis, has an impact on adrenal differentiation and growth also in the context of adrenal tumorigenesis. Accordingly, adrenocortical carcinoma frequently lack MC2-R expression, a phenotype which is associated with a more aggressive
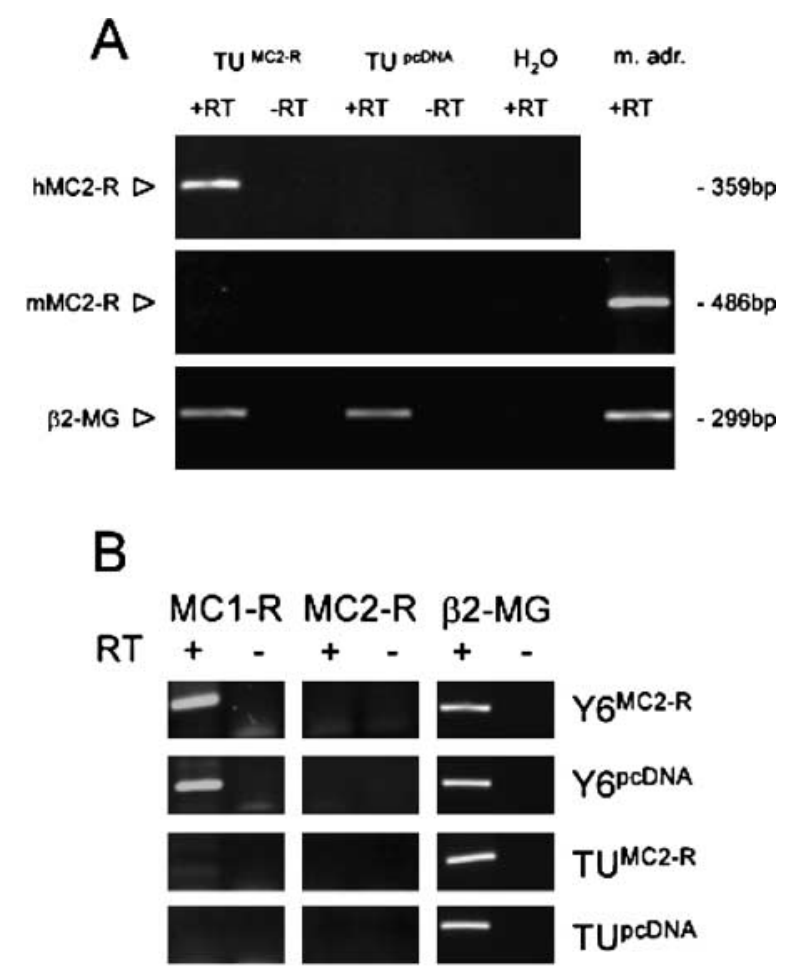

Figure 5 (A) RT-PCR of tumor samples demonstrating retained expression of human ACTH receptor (hMC2-R) mRNA in transfected tumors (TU ${ }^{\mathrm{MC} 2-\mathrm{R}}$ ) while endogenous murine MC2-R (mMC2-R) is not expressed after in vivo passage. A mouse adrenal cDNA (m. adr.) served as a positive control. DNA contamination was excluded by samples without reverse transcription (-RT). TU ${ }^{\text {pcDNA }}$ denotes control tumors transfected with empty vector. Two tumors from each treatment group were analyzed with reproducible results. Beta 2 microglobulin ( $\beta 2-M G)$ served as an internal control. (B) While melanocortin 1 receptor $(M C 1-R)$ is expressed in both MC2-R positive ( $\mathrm{Y}^{\mathrm{MC} 2-\mathrm{R}}$ ) and $\mathrm{MC2}-\mathrm{R}$ negative $\left(\mathrm{Y}^{\text {pcDNA }}\right.$ ) cell lines, MC1-R expression is lost in both tumor samples ( $T U^{\mathrm{MC}-\mathrm{R}}$ and TU ${ }^{\mathrm{pCDNA}}$ ) following passage in the animals. tumor growth and poor prognosis (4, 11, 12, 40). To date, it is not clear, however, whether this loss of MC2-R expression plays a causative role in adrenal tumorigenesis or is the mere result of the development of advanced tumor stages with an overall less differentiated phenotype. Herein, we present evidence that MC2-R expression is, in fact, closely related to a less aggressive adrenal tumor phenotype which can be amplified by ACTH treatment. We furthermore demonstrate that activation of MC2-R dependent pathways results in suppression of proliferation, while apoptosis and cellular hypertrophy are not affected by ACTH treatment in this tumor model. Although the decrease in the proliferation marker PCNA associated with the presence of MC2-R was modest, these changes were sufficient to cause significant growth retardation with lower tumor weight in comparison to tumors lacking MC2-R expression.

Functional in vitro expression of the MC2-R has been difficult to achieve, because of the presence of MC1-R with background activity after stimulation with ACTH $(41,42)$ or because of failed retained receptor protein in the endoplasmatic reticulum (43) most likely due to the lack of the recent cloned melanocortin 2 receptor accessory protein (MRAP) (44). Y6 cells which have been derived from the Y1 adrenocortical tumor cell line as ACTH resistant cell clones have been characterized by defective expression of wild type MC2-R, despite a normal DNA sequence encoding that receptor while retaining signaling properties induced by forskolin (37). Accordingly, these cells have successfully been utilized in transfection models to demonstrate the characteristics of mutant MC2-R in vitro that were identified in patients with familial glucocorticoid deficiency (45). Although the cellular phenotype of Y6 cells is linked to a polymorphism of the transcription factor SF-1, the underlying molecular defect that affects SF-1 function has not been elucidated in detail (46). As we demonstrate, MC2-R expression can be maintained after stable transfection even after passage in vivo, and restoration of MC2-R expression has a significant impact on tumor physiology. In contrast to normal adrenocortical cells, ACTH has no significant effect on cellular hypertrophy in this tumor model, a feature that might be associated with the overall low steroidogenic properties of this cell line (47).

It has to be noted that ACTH treatment did also affect growth of MC2-R negative tumors, although to a lesser extent than MC2-R expressing tumors and without reaching statistical significance. In mice, ACTH has low affinity to the MSH receptor, MC1-R $(48,49)$, therefore, we hypothesized that higher doses of ACTH might activate MC1-R dependent pathways and may affect the tumor phenotype independently of MC2-R expression. Thus, we investigated the Y6 cell lines and the resulting tumors for MC1R expression. Interestingly, although MC1-R expression could be demonstrated in our strains of the parental Y6 cell lines, its expression 
was lost following the passage in the animals. Tumors are prone to change their biological phenotype through chromosomal instability, increased mutation rate and transcriptional regulation that result in the growth advantage of certain tumor clones. In this context, loss of MC1-R expression in the course of tumor development might be interpreted as loss of differentiation in these tumor clones. However, ACTH dependent effects on adrenal tumor growth in this model are not to be explained by activation of MC1-R dependent pathways.

As in all complex in vivo models, direct treatment effects have to be differentiated from possible indirect effects that might have impact on the overall phenotype. Such possible indirect effects that could affect adrenal tumor growth include alteration of the endogenous hypothalamus-pituitary-adrenal (HPA) axis by exogenous ACTH treatment. Higher doses of ACTH such as those given in our study increase adrenal steroidogenesis and it cannot be excluded that elevated glucocorticoid levels might directly affect adrenocortical tumor growth. In addition, and in accordance with the hypothesis that the pro- $\gamma$-MSH fraction of POMC harbors a peptide with mitogenic properties to the adrenal cortex (23, 50 ), the glucocorticoid induced suppression of endogenous POMC might also have affected adrenal tumor growth. To circumvent these disturbances, we chose ACTH doses that did not cause overt hypercortisolism as demonstrated by the lack of significant changes in corticosterone and endogenous ACTH levels at the end of the study. As more subtle indicators of long term ACTH bioactivity, adrenal weights as markers of ACTH induced adrenal hypertrophy and thymus weights as markers of glucocorticoid action on lymphatic tissue were assessed and did not show significant differences between the treatment groups. However, time course experiments after the injection of a slow release form of ACTH 1-24 disrupts the physiological diurnal rhythm of HPA axis activity with intermittently elevated blood levels of total ACTH. In this respect, it could be argued that the small decrease in MC2-R negative tumor cells upon ACTH treatment might be due to lower levels of endogenous N-POMC peptides levels, thus adding another facet to mechanisms of ACTH dependent suppression of adrenal tumor growth.

Taken together, we demonstrate a growth inhibiting effect of ACTH 1-24 in an in vivo adrenocortical tumor model using high physiological doses of ACTH. We present evidence that this effect is most likely independent of pituitary function and corticosterone levels, suggesting direct effects of ACTH treatment on adrenocortical tumor growth. Novel treatment options for patients with adrenocortical carcinoma are urgently needed. Based on our data, it seems reasonable to speculate about possible clinical applications of antiproliferative actions of ACTH. For example, in patients with adrenocortical carcinoma, combined treatment of low doses of ACTH with differentiation inducing agents such as peroxisome proliferator activated recep- tor (PPAR). $\gamma$ agonists that antagonize loss of MC2-R expression in adrenocortical carcinoma (51) might be considered a compelling future concept.

\section{Acknowledgements}

We are indebted to Roger Cone and Bernard Schimmer for their generous gift of an expression vector for human MC2-R and the Y6 cells, respectively. This work was supported by grants from the Deutsche Forschungsgemeinschaft (DFG, Re 752/11-2.) and Mildred Scheel Stiftung to MR.

\section{References}

1 Mountjoy KG, Robbins LS, Mortrud MT \& Cone RD. The cloning of a family of genes that encode the melanocortin receptors. Science $19922571248-1251$.

2 Lotfi CF, Todorovic Z, Armelin HA \& Schimmer BP. Unmasking a growth-promoting effect of the adrenocorticotropic hormone in Y1 mouse adrenocortical tumor cells. Journal of Biological Chemistry $199727229886-29891$.

3 Gallo-Payet N \& Payet MD. Mechanism of action of ACTH: beyond cAMP. Microsc Res Tech 200361 275-287.

4 Allolio B, Hahner S, Weismann D \& Fassnacht M. Management of adrenocortical carcinoma. Clinical Endocrinology $2004 \mathbf{6 0}$ 273-287.

5 Latronico AC, Reincke M, Mendonca BB, Arai K, Mora P, Allolio B, Wajchenberg BL, Chrousos GP \& Tsigos C. No evidence for oncogenic mutations in the adrenocorticotropin receptor gene in human adrenocortical neoplasms. Journal of Clinical Endocrinology and Metabolism $1995 \mathbf{8 0} 875-877$.

6 Light K, Jenkins PJ, Weber A, Perrett C, Grossman A, Pistorello M, Asa SL, Clayton RN \& Clark AJ. Are activating mutations of the adrenocorticotropin receptor involved in adrenal cortical neoplasia? Life Sciences 199556 1523-1527.

7 Reincke M, Karl M, Travis W \& Chrousos GP. No evidence for oncogenic mutations in guanine nucleotide-binding proteins of human adrenocortical neoplasms. Journal of Clinical Endocrinology and Metabolism 199377 1419-1422.

8 Fragoso MC, Domenice S, Latronico AC, Martin RM, Pereira MA, Zerbini MC, Lucon AM \& Mendonca BB. Cushing's syndrome secondary to adrenocorticotropin-independent macronodular adrenocortical hyperplasia due to activating mutations of GNAS1 gene. Journal of Clinical Endocrinology and Metabolism $2003 \mathbf{8 8}$ 2147-2151.

9 Lyons J, Landis CA, Harsh G, Vallar L, Grunewald K, Feichtinger H, Duh QY, Clark OH, Kawasaki E \& Bourne HR. Two G protein oncogenes in human endocrine tumors. Science $1990 \mathbf{2 4 9}$ 655-659.

10 Reincke M, Beuschlein F, Menig G, Hofmockel G, Arlt W, Lehmann R, Karl M \& Allolio B. Localization and expression of adrenocorticotropic hormone receptor mRNA in normal and neoplastic human adrenal cortex. Journal of Endocrinology 1998156 415-423.

11 Reincke M, Beuschlein F, Latronico AC, Arlt W, Chrousos GP \& Allolio B. Expression of adrenocorticotrophic hormone receptor mRNA in human adrenocortical neoplasms: correlation with P450scc expression. Clinical Endocrinology 199746 619-626.

12 Reincke M, Mora P, Beuschlein F, Arlt W, Chrousos GP \& Allolio B. Deletion of the adrenocorticotropin receptor gene in human adrenocortical tumors: implications for tumorigenesis. Journal of Clinical Endocrinology and Metabolism 199782 3054-3058.

13 Clark AJ \& Weber A. Adrenocorticotropin insensitivity syndromes. Endocrine Reviews 199819 828-843. 
14 Cater DB \& Stack-Dunne MP. The histological changes in the adrenal of the hypophysectomised rat after treatment with pituitary preparations. Journal of Pathology and Bacteriology $1953 \mathbf{6 6}$ 119-133.

15 Mazzocchi G, Malendowicz LK, Rebuffat P, Robba C, Gottardo G \& Nussdorfer GG. Short- and long-term effects of ACTH on the adrenal zona glomerulosa of the rat. A coupled stereological and enzymological study. Cell and Tissue Research 1986243 303-310.

16 Coll AP, Challis BG, Yeo GS, Snell K, Piper SJ, Halsall D, Thresher RR \& O'Rahilly S. The effects of proopiomelanocortin deficiency on murine adrenal development and responsiveness to adrenocorticotropin. Endocrinology $20041454721-4727$.

17 Masui H \& Garren LD. On the mechanism of action of adrenocorticotropic hormone. The stimulation of thymidine kinase activity with altered properties and changed subcellular distribution. Journal of Biological Chemistry $1971 \mathbf{2 4 6} 5407-5413$.

18 Masui H \& Garren LD. On the mechanism of action of adrenocorticotropic hormone. Stimulation of deoxyribonucleic acid polymerase and thymidine kinase activities in adrenal glands. Journal of Biological Chemistry $1970 \mathbf{2 4 5} 2627-2632$.

19 Payet N, Lehoux JG \& Isler H. Effect of ACTH on the proliferative and secretory activities of the adrenal glomerulosa. Acta Endocrinologica 198093 365-374.

20 Estivariz FE, Iturriza F, McLean C, Hope J \& Lowry PJ. Stimulation of adrenal mitogenesis by N-terminal proopiocortin peptides. Nature $1982 \mathbf{2 9 7} 419-422$.

21 Estivariz FE, Carino M, Lowry PJ \& Jackson S. Further evidence that N-terminal proopiomelanocortin peptides are involved in adrenal mitogenesis. Journal of Endocrinology $1988 \mathbf{1 1 6}$ 201-206.

22 Lowry PJ, Silas L, McLean C, Linton EA \& Estivariz FE. Pro-gammamelanocytestimulating hormone cleavage in adrenal gland undergoing compensatory growth. Nature 1983306 70-73.

23 Bicknell AB, Lomthaisong K, Woods RJ, Hutchinson EG, Bennett HP, Gladwell RT \& Lowry PJ. Characterization of a serine protease that cleaves pro-gammamelanotropin at the adrenal to stimulate growth. Cell 2001 105 903-912.

24 Masui H \& Garren LD. Inhibition of replication in functional mouse adrenal tumor cells by adrenocorticotropic hormone mediated by adenosine $3^{\prime}: 5^{\prime}$-cyclic monophosphate. PNAS 1971 68 3206-3210.

25 Weidman RE \& Gill GN. Differential effects of ACTH or 8-Dr-cAMP on growth and replication in a functional adrenal tumor cell line. Journal of Cellular Physiology 197790 91-103.

26 Morera AM \& Saez JM. In vitro mitogenic and steroidogenic effects of ACTH analogues on an adrenal tumor cell line (Y-1). Experimental Cell Research 1980127 446-451.

27 Ramachandran J \& Suyama AT. Inhibition of replication of normal adrenocortical cells in culture by adrenocorticotropin. PNAS 197572 113-117.

28 Gospodarowicz D \& Handley HH. Stimulation of division of Y1 adrenal cells by a growth factor isolated from bovine pituitary glands. Endocrinology 197597 102-107.

29 Hornsby PJ \& Gill GN. Hormonal control of adrenocortical cell proliferation. Desensitization to ACTH and interaction between ACTH and fibroblast growth factor in bovine adrenocortical cell cultures. Journal of Clinical Investigation $197760342-352$.

30 Simonian MH \& Gill GN. Regulation of the fetal human adrenal cortex: effects of adrenocorticotropin on growth and function of monolayer cultures of fetal and definitive zone cells. Endocrinology $1981 \mathbf{1 0 8} 1769-1779$.

31 Armato U, Andreis PG, Draghi E \& Meneghelli V. Primary tissue culture of normal adult human decapsulated adrenal cortex: radioautographic studies on the metabolic effects of ACTH1-24. Hormone Research 19756 105-115.

32 Armato U, Nussdorfer GG, Neri G, Draghi E, Andreis PG, Mazzocchi G \& Mantero F. Effects of ACTH and $3^{\prime}, 5^{\prime}$-cyclic purine nucleotides on the morphology and metabolism of normal adult human adrenocortical cells in primary tissue culture. Cell and Tissue Research $1978190187-205$.
33 Menapace L, Armato U \& Whitfield JF. The effects of corticotrophin (ACTH1-24), cyclic AMP and TPA (12-O-tetradecanoyl phorbol13-acetate) on DNA replication and proliferation of primary rabbit adrenocortical cells in a synthetic medium. Biochemical and Biophysical Research Communication 1987148 1295-1303.

34 Arola J, Heikkila P \& Kahri AI. Biphasic effect of ACTH on growth of rat adrenocortical cells in primary culture. Cell and Tissue Research 1993271 169-176.

35 Kimura E, Sonobe MH, Armelin MC \& Armelin HA. Induction of FOS and JUN proteins by adrenocorticotropin and phorbol ester but not by $3^{\prime}, 5^{\prime}$-cyclic adenosine monophosphate derivatives. Molecular Endocrinology 19937 1463-1471.

36 Viard I, Penhoat A, Ouali R, Langlois D, Begeot M \& Saez JM. Peptide hormone and growth factor regulation of nuclear protooncogenes and specific functions in adrenal cells. Journal of Steroid Biochemistry and Molecular Biology 199450 219-224.

37 Schimmer BP, Kwan WK, Tsao J \& Qiu R. Adrenocorticotropinresistant mutants of the $\mathrm{Y} 1$ adrenal cell line fail to express the adrenocorticotropin receptor. Journal of Cellular Physiology 1995 $163164-171$.

38 Qiu R, Tsao J, Kwan WK \& Schimmer BP. Mutations to forskolin resistance result in loss of adrenocorticotropin receptors and consequent reductions in levels of $\mathrm{G}$ protein alpha-subunits. Molecular Endocrinology $1996 \mathbf{1 0} 1708-1718$.

39 Boston BA \& Cone RD. Characterization of melanocortin receptor subtype expression in murine adipose tissues and in the 3T3-L1 cell line. Endocrinology $19961372043-2050$.

40 Zwermann O, Beuschlein F, Klink A, Stahl M \& Reincke M. The role of the ACTH receptor in adrenal tumors: identification of a novel microsatellite marker. Hormone and Metabolic Research $200436406-410$.

41 Naville D, Barjhoux L, Jaillard C, Faury D, Despert F, Esteva B, Durand P, Saez JM \& Begeot M. Demonstration by transfection studies that mutations in the adrenocorticotropin receptor gene are one cause of the hereditary syndrome of glucocorticoid deficiency. Journal of Clinical Endocrinology and Metabolism 1996 81 1442-1448.

42 Weber A, Kapas S, Hinson J, Grant DB, Grossman A \& Clark AJ. Functional characterization of the cloned human ACTH receptor: impaired responsiveness of a mutant receptor in familial glucocorticoid deficiency. Biochemical and Biophysical Research Communications $1993197172-178$.

43 Noon LA, Franklin JM, King PJ, Goulding NJ, Hunyady L \& Clark AJ. Failed export of the adrenocorticotrophin receptor from the endoplasmic reticulum in non-adrenal cells: evidence in support of a requirement for a specific adrenal accessory factor. Journal of Endocrinology 2002 174 17-25.

44 Metherell LA, Chapple JP, Cooray S, David A, Becker C, RuschendorfF, Naville D, Begeot M, Khoo B, Nurnberg P, Huebner A, Cheetham ME \& Clark AJ. Mutations in MRAP, encoding a new interacting partner of the ACTH receptor, cause familial glucocorticoid deficiency type 2 . Nature Genetics 200537 166-170.

45 Elias LL, Huebner A, Pullinger GD, Mirtella A \& Clark AJ. Functional characterization of naturally occurring mutations of the human adrenocorticotropin receptor: poor correlation of phenotype and genotype. Journal of Clinical Endocrinology and Metabolism $1999842766-2770$.

46 Frigeri C, Tsao J, Cordova M \& Schimmer BP. A polymorphic form of steroidogenic factor-1 is associated with adrenocorticotropin resistance in y 1 mouse adrenocortical tumor cell mutants. Endocrinology $2002 \mathbf{1 4 3} 4031-4037$.

47 Schimmer BP, Cordova M, Tsao J \& Frigeri C. A polymorphic form of steroidogenic factor 1 associated with ACTH receptor deficiency in mouse adrenal cell mutants. Annals of the New York Academy of Sciences $2003994147-153$.

48 Gallo-Payet N \& Escher E. Adrenocorticotropin receptors in rat adrenal glomerulosa cells. Endocrinology $198511738-46$.

49 Abdel-Malek ZA. Melanocortin receptors: their functions and regulation by physiological agonists and antagonists. Cellular and Molecular Life Sciences 200158 434-441. 
50 Fassnacht M, Hahner S, Hansen IA, Kreutzberger T, Zink M, Adermann K, Jakob F, Troppmair J \& Allolio B. N-terminal proopiomelanocortin acts as a mitogen in adrenocortical tumor cells and decreases adrenal steroidogenesis. Journal of Clinical Endocrinology and Metabolism $2003 \mathbf{8 8} 2171-2179$.

51 Betz MJ. Shapiro I, Fassnacht M, Hahner S, Reincke M \& Beuschlein F. Peroxisome proliferator activated receptor gamma (PPAR $\gamma)$ agonists suppress adrenocortical tumor cell proliferation and induce differentiation. Journal of Clinical Endocrinology and Metabolism 200590 3886-3896.

Received 1 February 2005

Accepted 16 June 2005 